\title{
In-Situ Diagnostics and Prognostics of Wire Bonding Faults in IGBT Modules for Electric Vehicle Drives
}

\author{
Bing Ji, Member, IEEE, Volker Pickert, Member, IEEE, \\ Wenping Cao*, Senior Member, IEEE, Bashar Zahawi, Senior Member, IEEE
}

\begin{abstract}
This paper presents a diagnostic and prognostic condition monitoring method for IGBT power modules for use primarily in electric vehicle applications. The wire bond related failure, one of the most commonly observed packaging failures, is investigated by analytical and experimental methods using the on-state voltage drop as a failure indictor. A sophisticated test bench is developed to generate and apply the required current/power pulses to the device under test. The proposed method is capable of detecting small changes in the failure indicators of the IGBTs and freewheeling diodes (FWDs) and its effectiveness is validated experimentally. The novelty of the work lies in the accurate online testing capacity for diagnostics and prognostics of the power module with a focus on the wire bonding faults, by injecting external currents into the power unit during the idle time. Test results show the IGBT may sustain a loss of half the bond wires before the impending fault becomes catastrophic. The measurement circuitry can be embedded in the IGBT drive circuits and the measurements can be performed in-situ when the electric vehicle stops in stop-and-go, red light traffic conditions or during routine servicing.
\end{abstract}

Index Terms - Electric vehicles, heating, insulated gate bipolar transistors, monitoring, power electronics, reliability testing.

\section{INTRODUCTION}

$\mathrm{O}$ VER THE last 20 years, electric vehicle (EV) technologies have taken a significant leap forward, primarily aided by advances in electrical motor drives, power converters, batteries and system configuration. Generally, EVs can be classifies as hybrid electric vehicles (HEVs), plug-in hybrid electric vehicles (PHEVs), more electric vehicles (MEVs) and all electric vehicles (AEVs), depending on the electrification level of the vehicles. EVs represent a cost-sensitive market and new technologies are under development to improve their system performance while driving down the cost. In addition to initial costs, the reliability of key components is an important performance indicator which affects operational costs and could make the difference between success and failure of a concept in the marketplace.

Power electronic converters are widely used in electric traction drive applications [1]-[9] while multi-chip insulated-gate bipolar transistor (IGBT) power modules are the most commonly used power switches for the EVs' on-board power converters [10][11]. However, IGBTs are known to be prone to failure [12]-[19], and the situation would only get worse when operating in the harsh environment beneath the bonnet of an electric vehicle. Table I presents typical environmental conditions and operational requirements for automotive applications [13][20]. Clearly, the performance and reliability of IGBT modules are constrained by these stringent conditions which lead to exposure to high temperatures, high levels of humidity, extreme cyclic loading and mechanical stress [21]-[25]. Among these, thermo-mechanical stress is an overriding factor that causes IGBT packaging connector fatigue [12][26]-[30] (such as bond wire and solder connection failures). Because of improved solder technologies [31]-[32], wirebonds are generally observed as the major type of packaging failures to reduce the lifetime of IGBTs [19][33]-[35] and thus are the focus of this paper.

\section{TABLE I}

ENVIRONMENTAL CONDITIONS AND OPERATIONAL REQUIREMENTS

\begin{tabular}{ll}
\hline \hline \multicolumn{1}{c}{ Parameter } & \multicolumn{1}{c}{ Value } \\
\hline Ambient air temperature & $-40^{\circ} \mathrm{C}$ to $135^{\circ} \mathrm{C}$ \\
Coolant water temperature & $-40^{\circ} \mathrm{C}$ to $105^{\circ} \mathrm{C}$ \\
Junction temperature & $-40^{\circ} \mathrm{C}$ to $175^{\circ} \mathrm{C}$ \\
Temperature cycling & 1000 cycles $@ \Delta \mathrm{T}=165^{\circ} \mathrm{C}$ \\
Power cycling & 30,000 cycles $@ \Delta \mathrm{T}=100^{\circ} \mathrm{C}$ \\
Humidity & $85 \%$ \\
Vibration & $10 \mathrm{~g}$ \\
Shock & $50 \mathrm{~g}$ \\
Operational life & $131,400 \mathrm{~h}$ \\
\hline \hline
\end{tabular}

At present, wire bonding is the dominant technology used to connect the terminals (or leads) to the semiconductor chips because this is still a straightforward, flexible and cost-effective solution. Recent advances in new composition wire materials [36] and new bonding technologies (e.g. special coating and strain buffer bonding [12]) have received much attention by the industry. Nonetheless, when the bonding using these new technologies fails, the entire device will be damaged with catastrophic consequences.

Without a doubt, the detection of an IGBT fault prior to (prognosis) or even after (diagnosis) its occurrence is of critical importance to the healthy operation of the system. Conventional vehicles are equipped with an on-board diagnostic (OBD) system which can detect a "happened" fault and flag it up to the driver of the vehicle. In the event of an IGBT failure, the detection must be quick enough (ideally, less than $10 \mu \mathrm{s}$ ) to prevent a fault from propagating, which places a limit on the hardware setup [37]-[40]. Obviously, there is an increasing need for prognostic detection technologies to provide state-of-health or early warning 
information. Traditional reliability prediction methods include Mil-HDBK-217, 217-PLUS, PRISM, Telcordia and FIDES. These are empirical methods based on statistical data and average performance of a large number of identical products. In essence, they account little for the mechanisms of complex in-service failures. It is thus not surprising that the results obtained from these methods do not always correlate well with actual failures in the field [41].

Recently, some advanced prognostic techniques have been proposed to predict semiconductor devices' impending failures. First, a range of detecting elements may be embedded within the host device and their failures provide an early warning signal. This is called the Canary method [42]. The second method is the analytical lifetime prediction based on Coffin-Manson models [43][44], Norris-Landzberg models [45][46], or Bayerer's models [47]. The lifetime expectancy (in numbers of cycles) of an IGBT is experimentally obtained from new at given environmental and load conditions. The cumulative fatigue (or damage) of an IGBT is calculated based on actual operational conditions and its remaining useful life (RUL) is then expressed as the number of cycles to failures [25][48][49]. The third method is the failure precursor method. This is realized by observing changes in either fault-related parameters [28] or by adding purpose-built embedded sensors [50][51]. All these methods have advantages and drawbacks. The first method is technically effective but provides limited information of device life consumption. It is irreversible and also affects the system architecture of the chip. The second can offer quantitative information of the RUL from exhaustive tests but the parameters associated with different stress conditions are not fully considered. For instance, humidity and mechanical stress are key parameters but are not accounted for. The third method is indirect and easy to implement while the complex relationship between failures and precursors is over simplified. Overall, failure mechanisms have not been fully understood and these methods cannot be applied in service conditions.

This work evolves from the third method and extends it to in-situ condition monitoring (CM) of IGBTs and free-wheeling diodes (FWDs). The monitoring circuitry can be embedded in an advanced gate drive unit (GDU) while the diagnostic and prognostic tests can be conducted during stop-and-go traffic conditions or routine services.

The paper is organized as follows. Wire bond failure mechanisms and their prognostic parameters are explained in Section II. An on-board condition monitoring system is presented for practical applications in Section III. The analytical and experimental work is described and discussed in Section IV, followed by the conclusions in Section V.

\section{FAILURe Mechanisms AND Prognostic PARAMEters}

All conventional power modules have a structure of multiple layers. The schematic cross-section of a wire-bonded IGBT module is shown in Fig. 1. When viewed from the top, the aluminum wire is bonded to the chip top metallization to connect the semiconductor chips, as in the case of IGBTs and FWDs. The silicon chips are soldered onto a metal plated ceramic substrate, which is soldered onto the baseplate. The IGBT module is encapsulated with silicone gel to increase its physical integrity.

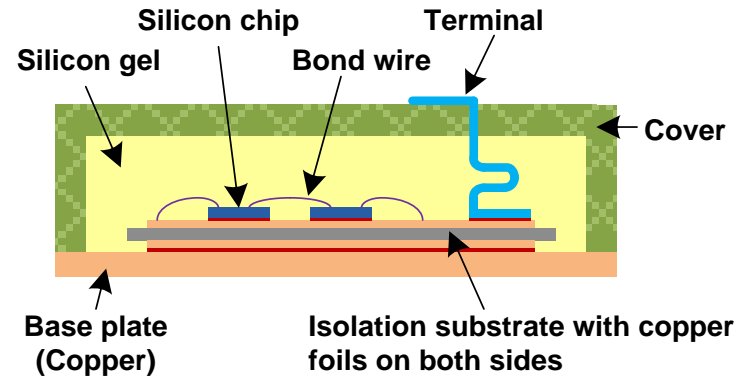

Fig.1 Schematic cross-section of the IGBT power module.

\section{A. Failure mechanisms of wire bonds}

During normal operation of IGBTs, semiconductor chips will generate heat and pass it by conduction onto the heat sink through layers of components, leading to a temperature gradient within the multilayer structure and thus a thermo-mechanical stress. Similarly, as the ambient or junction temperature varies, a thermo-mechanical stress is also created on layer interfaces as well as within each layer. These can be explained by thermal expansion as in $\mathrm{Eq}(1)$,

$$
\frac{\Delta l}{l}=C T E \times \Delta T
$$

where $l$ and $\Delta l$ are the length and its deviation subject to a temperature gradient $\Delta T$, and CTE stands for the coefficient of thermal expansion.

Table II gives the CTE values for common materials used in IGBTs. Because the layers of IGBTs are made of materials with different CTEs, a physical departure or crack may be created after undergoing repetitive thermal cycling, power cycling or mechanical stress during operation. This is particularly pertinent for electric vehicle applications [13][20] because the operation of vehicles involves frequent acceleration, regenerative braking and cruising. Among major causes, the repetitive temperature swing account for the majority of long-term packaging-related wear-out failures. For every $10^{\circ} \mathrm{C}$ increase in the operating environment, the failure rate is doubled [52]. Typical junction temperature swings resulting from both device self-heating and environmental temperature variations are illustrated in Fig. 2.

TABLE II

CTES OF COMMON ELECTRONIC MATERIALS

\begin{tabular}{llc}
\hline \hline \multicolumn{1}{c}{ Part } & \multicolumn{1}{c}{ Material } & $\mathrm{CTE}\left(\mathrm{ppm} /{ }^{\circ} \mathrm{C}\right)$ \\
\hline Silicone gel & Silicone resin & $30-300$ \\
Epoxy resin & Epoxy & $15-100$ \\
Terminal & Copper & 17.5 \\
Ni plating & Nickel & 13.4 \\
Solder layer & Solder & $15-30$ \\
Bond wire & Aluminum & 22.5 \\
Chip metallization & Aluminum & 22.5 \\
Chip & Silicon & 4.1 \\
Isolation substrate & Aluminum oxide & 8.3 \\
& Aluminum nitride & 5.7 \\
Baseplate & Copper & 17.5 \\
& Aluminum silicon carbide & $5-15$ \\
\hline \hline
\end{tabular}




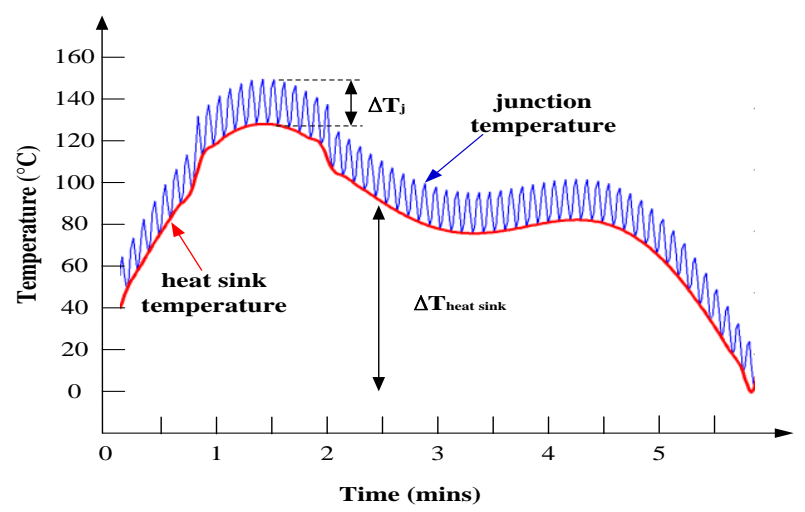

Fig. 2 Typical junction temperature swings of a power device.

In general, the wire bonding faults of IGBTs are caused by bonding wire lift-off, heel cracking or aluminum metallization reconstruction. Fig. 3 shows the images of these three damage accumulations at bonded interfaces. The damage generally starts from a tiny crack and can propagate over time to result in an open-circuit or a short-circuit failure. Furthermore, the deformation of bond wires and their length variations will also escalate the damage. IGBT modules always use multiple wires bonded in parallel to increase their current-carrying capability. If a bond wire is open-circuited due to a fault, current loading passing through other wires is increased and so is their temperature (self-heating). As a consequence, the aging process of IGBTs will be accelerated. The same is true for chip metallization reconstruction as it increases the contact resistance and joule loss. Obviously, all these adverse effects raise the temperature which may lead to the melting of the metal joints if left untreated. Moreover, the increased heat is also likely to pass through the silicon chip causing severe damages or malfunctions such as latch-up [12][18], hot-spots [12] or even burn-outs.

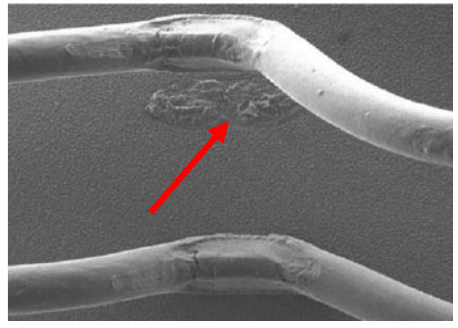

(a) Bond wire lift-off

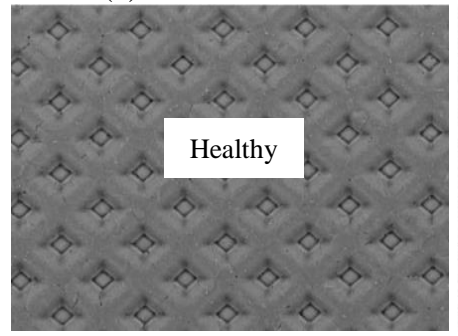

(c) Chip metallization reconstruction

Fig. 3 Photographs of three types of wire bonding faults [30].

\section{B. Prognostic parameters for detecting bond wire degradation}

IGBTs' bond wire fatigue and chip metallization reconstruction can be directly evaluated by measuring their shear stress or crack length. This normally calls for special equipment and is only implemented as offline measurements [53]. Since the IGBTs' aging process leads to progressive changes in their internal resistance and terminal voltage drop during forward conduction ( $\mathrm{V}_{\mathrm{CE}(\mathrm{on})}$ for IGBTs and $\mathrm{V}_{\mathrm{F}(\mathrm{on})}$ for FWDs), the two parameters can be used as prognostic health indicators to establish a correlation between ageing and impending failures of the devices [14][54].

Fig. 4 shows a photograph and the static equivalent circuit of a 70A half-bridge IGBT module SKM 50GB063D used in this work. In this figure, the device terminal voltage $\operatorname{drop}\left(V_{\mathrm{T}}\right)$ is given by the sum of the voltage drop across the silicon chip $\left(V_{\text {chip }}\right)$ and the voltage drop across the stray resistance $\left(V_{\text {stray }}\right)$. In principle, $V_{\text {chip }}$ varies with the junction temperature and load current. For IGBTs, it is also affected by the gate-emitter voltage. Also in the figure, the stray resistance is comprised of five parts: 1) the effective resistance across the bond wire and bonding interface $\left(\mathrm{R}_{\mathrm{EE}^{\prime} 1}, \mathrm{R}_{\mathrm{AA}}{ }^{\prime}\right.$,

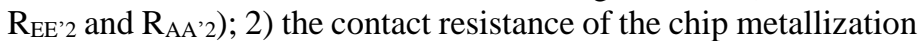
pad ( $\mathrm{R}_{\mathrm{ME}}{ }^{\prime}, \mathrm{R}_{\mathrm{MA}}{ }^{\prime} 1, \mathrm{R}_{\mathrm{ME}^{\prime 2} 2}$ and $\mathrm{R}_{\left.\mathrm{MA}^{\prime 2}\right)}$ ); 3) the resistance of the die

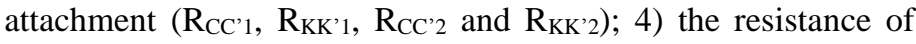
directly bonded copper layer $\left(\mathrm{R}_{\mathrm{Cu}}\right)$; and 5$)$ the resistance of the terminal and its contact $\left(\mathrm{R}_{\mathrm{L} 1}, \mathrm{R}_{\mathrm{L} 2}\right.$ and $\left.\mathrm{R}_{\mathrm{L} 3}\right)$.
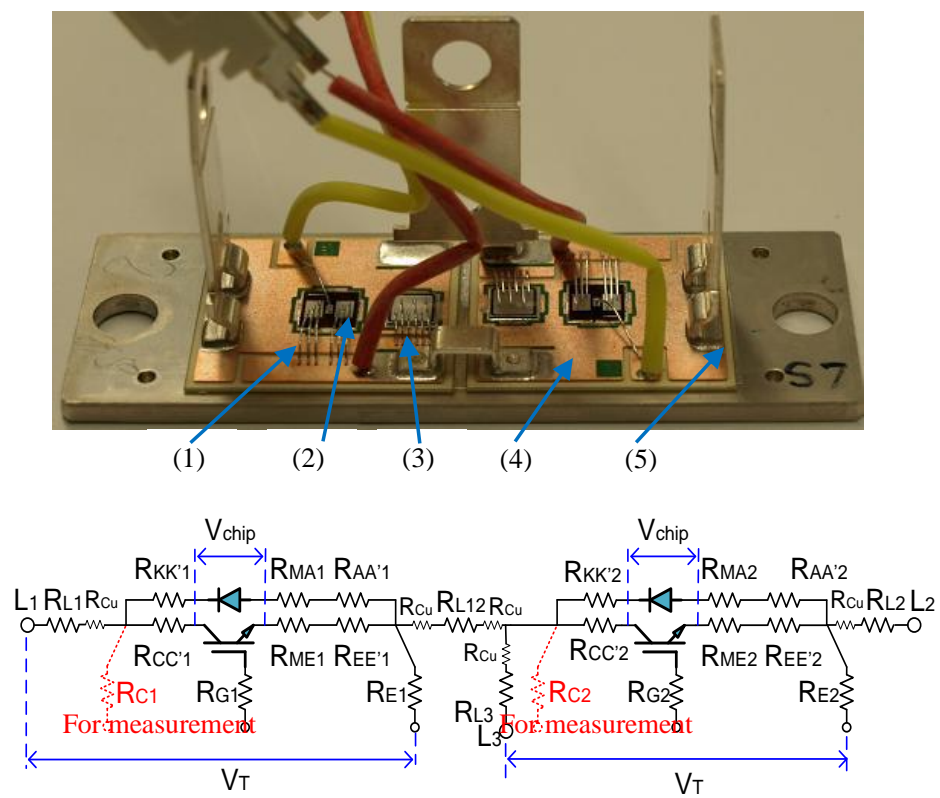

Fig. 4 Photograph and static equivalent circuit of a half-bridge IGBT module.

In addition to self-heating, parts 1-3 of the stray resistance would also experience substantial temperature swings arising from the operation of semiconductor chips they are directly connected to. Changes in parts 1-3 are key to the indication of the state of health of the IGBT and should be detected for prognostic purposes. Although parts 4 and 5 are not in the proximity of the chip (thus less likely to be affected by the chip's thermal cycles), they can still be affected by the degradation of the terminal lead joints which raises the contact resistance of the terminal joints, and in turn, increases the forward voltage drop [55]. For this reason, the IGBT's on-state voltage in this paper is measured between the collector power terminal and the Kelvin emitter terminal, rather than the voltage between the collector and emitter of the power terminals. 


\section{Proposed Diagnostic and Prognostic Method And EXPERIMENTAL SETUP}

As explained previously, existing diagnostic and prognostic methods are limited. One of the clear technical challenges is the extraction of small signals $(\mathrm{mV})$ from larger ones (hundreds of volts) meaning that conventional methods can not apply to in-situ measurements. That is, the variations in prognostic parameters resulting from ageing are relatively small so that measured signals can be overwhelmed by noise or disturbances in the EV power network which are associated with changes in operating conditions (temperature, loading or control). As a result, much effort in this work is directed at improving the measurement accuracy.

Fig. 5 shows photographs and schematic diagrams of the complete experimental setup. In Fig. 5(a), the DUTs (IGBTs) are placed in the thermal chamber to maintain a required testing environment and tested using the proposed on-board CM circuit. In Fig. 5(b), T1-T6 are six identical IGBTs, D1-D6 are six FWDs and $\mathrm{M}$ is an electric motor. The measurement circuitry consists of: 1) an auxiliary power supply unit (PSU); 2) a gate drive and protection circuit; 3) a measurement circuit with digital isolation; and 4) selector relays.

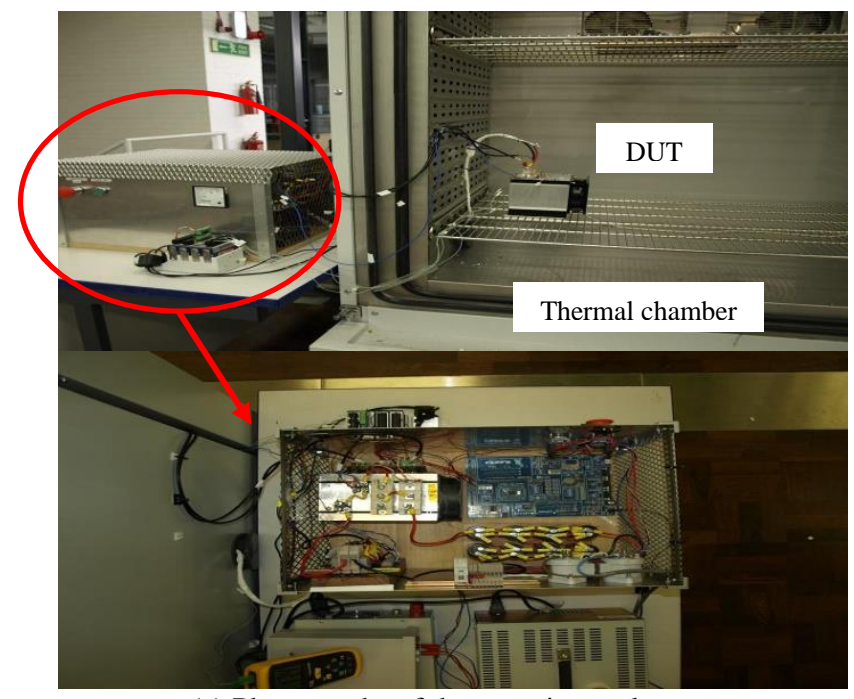

(a) Photographs of the experimental setup

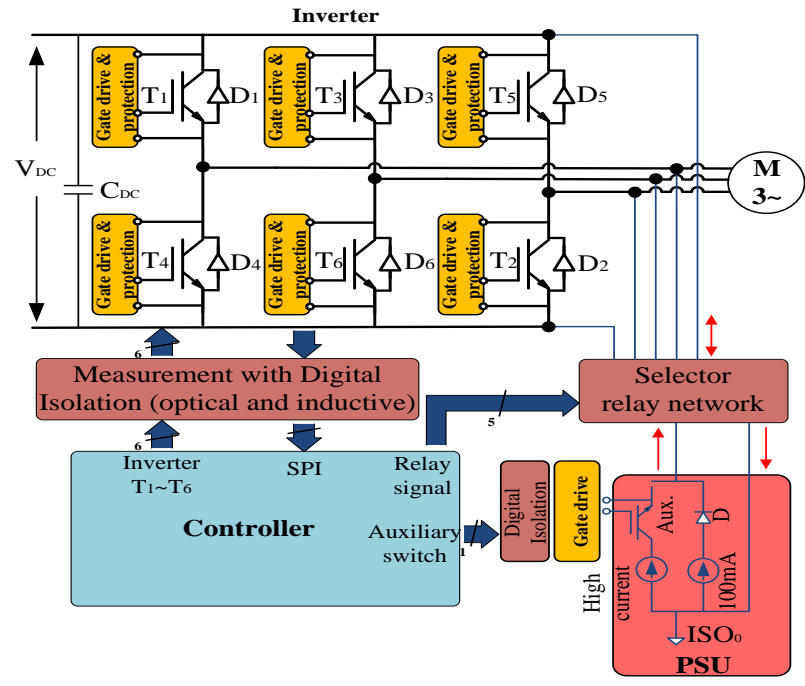

(b) The condition monitoring circuit within the EV power inverter
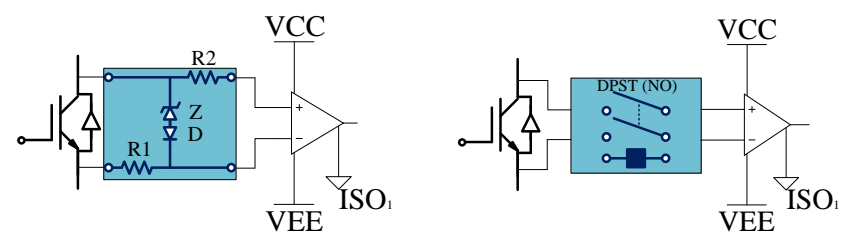

Zener protection voltage up to $600 \mathrm{~V}$ Relay protection $600-2500 \mathrm{~V}$

(c) Gate drive and protection circuit for two DC link voltage levels

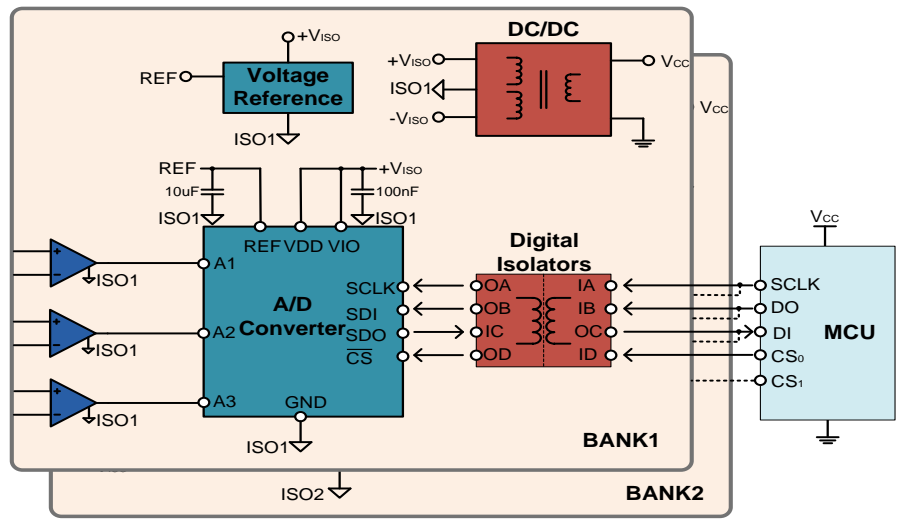

(d) Measurement with digital isolation

Fig. 5 The proposed in-situ measurement circuitry.

\section{A. Auxiliary power supply unit}

The auxiliary PSU is designed to inject current or power of predefined patterns into the device under test (DUT) during the condition monitoring procedure. The PSU is composed of two current sources: a low current source with a $100 \mathrm{~mA}$ output used for junction temperature measurements; and a high current source (50A) capable of generating high current pulse trains for condition monitoring purposes. The test currents are measured through a shunt resistor with Kelvin connection. A DC power supply is developed based on LAB-SM320 and used in this research work. For on-board measurements, it is also possible to utilize the EV battery as the power supply at the charger point $(12 \mathrm{Vdc})$.

\section{B. Gate drive and protection circuit}

Since condition monitoring should not disrupt other functions such as climate control and battery charging, the main contactor of the high voltage batteries needs to be engaged during condition monitoring. The $\mathrm{CM}$ process is implemented with an interrupt routine (I-monitoring) and activated repeatedly when the motor drive is idle. Consequently, a large portion of the DC link voltage will appear across the device during its off-state, which can be hundreds of times greater than the observed device on-state voltage. This high voltage is not used for diagnostic and prognostic functions and should be filtered out by a filter/protection circuit. In this case, a voltage divider circuit is not appropriate since it would also scale down the small diagnostic signals, resulting in a reduced signal-to-noise ratio (SNR). In the literature, an analog multiplexer circuit has been proposed to filter out the high off-state voltage [38] but the multiplexer itself needs to be protected from the high off-state voltage and extreme voltage spikes arising from switching transients. Thereafter, two off-state protection circuits are devised that can be embedded in the GDU as shown in Fig. 5(c). Zener protection and relay protection can be used to cater for medium (up to $600 \mathrm{~V}$ ) and high (600-2500V) DC link voltages, respectively. A voltage clamping 
circuit with a Zener diode $(Z)$ with a zener voltage of $10 \mathrm{~V}$ is employed to clamp the device off-state voltage. The Zener voltage should be less than the maximum allowable input voltage of the subsequent op-amp in order to avoid saturation. A diode $(D)$ with a low stray capacitance is connected in series with the Zener diode to reduce the effective stray capacitance. The value of the current-limiting resistor $\left(R_{1}\right)$ is chosen taking account of the Zener power rating requirement and the response time of the filter formed by $Z, D$ and $R_{1}$. Another resistor $\left(R_{2}\right)$ with the same value as $R_{1}$ is added to the low impedance side to balance the input impedance network. This helps minimize the common-mode error. However, the voltage clamping circuit suffers from an inherent leakage current, which can be very large at high DC-link voltages during the off-state of the power switch. Therefore, a relay protection is adopted for the high voltage condition. In this case, the voltage amplifier is gated to negate the switching transients and high voltage during the device off-state.

\section{Measurement circuit with digital isolation}

The power switches are exposed to extreme transient voltages and common-mode voltages (CMV) that affect measurement accuracy and may cause damage to the sensitive measuring equipment. In the in-situ measurement, signals are transmitted in both directions in the GDU so that a mechanism should be put in place to provide isolation between the low-voltage control unit and the high-voltage device. An isolated DC-DC converter and galvanic isolation are selected for transistor gating in conventional GDUs. In this study, a digital isolation technique is employed to interface diagnostic and prognostic signals with the control unit. Compared to analog isolation (e.g. isolation amplifier and analog optocoupler), digital isolation provides better transfer speed, lower error and reduced cost. As shown in Fig. 5(d), the front-end measurement system is powered by the isolated DC-DC converter of the GDU and includes an isolated 16-bit analog input signal interface. Measurement channels are created through two isolated banks. Bank 1 shares a single reference point ISO1 which is the positive DC bus voltage while Bank 2 shares a single reference point ISO2 which is the negative DC bus voltage. Digital isolation eliminates troublesome ground loop noise and differential inputs can be used to minimize the measurement noise. The isolation circuit is capable of handling signal inputs at $125 \mathrm{k}$ samples per channel per second.

\section{Selector relays}

In the experiments, each IGBT and FWD of the power module is tested independently in a sequence which is realized by a selector switch. The selector connecting the DUT with the PSU consists of a relay network. During IGBT diagnostic and prognostic tests, only the IGBT under test is switched on and other IGBTs are switched off so that no current is injected from the DC link. When a FWD is tested, all IGBT switches are turned off. By doing so, all IGBT switches and diodes can be measured individually and with precision. In this setup, a 10ms switching delay-time (based on the relay specifications) between two consecutive tests is added to the monitoring time. The total time for detecting wire bonding conditions of all devices in an EV power converter (6 IGBTs and 6 diodes) is very short (approximately $200 \mathrm{~ms}$ ). As a result, in-situ tests can be realistically performed during key-on/key-off, stop-and-go traffic conditions or during routine servicing.

\section{RESUlTS AND ANALYSIS}

In the test bench developed for diagnostics and prognostics of IGBT power modules, three half-bridge open modules of SKM 50GB063D are mounted on a forced air-cooled heat sink. Prior to any damage tests, the healthy baselines of the brand new IGBT modules are obtained from measurements and are later used as the benchmark for predicting bond wire degradation. In this study, bond wire faults are generated by cutting off the bond wires one by one (up to four bond wires in a six-wired IGBT). The reasons for this arrangement are two: one is to focus the attention on wire bonding faults. i.e., other effects such as solder fatigue and chip ageing are not involved; the other is to shorten the duration of experimental tests. Under each faulty condition, the failure precursors $\left(\mathrm{V}_{\mathrm{CE}(\mathrm{on})}\right.$ and $\left.\mathrm{V}_{\mathrm{F}(\mathrm{on})}\right)$ are measured and compared with the healthy baselines of the device. As a consequence, the condition of the bonding faults in IGBTs can be estimated with confidence.

\section{A. Junction temperature measurement}

As the failure mechanisms of the power devices are linked with their operating temperature, the information of chip temperature is a prerequisite for precursor extractions [28][54]. Because many IGBT parameters are temperature dependent, it is possible to use these parameters for estimating the temperature indirectly. In this paper, a temperature sensitive electrical parameter (TSEP) method is adopted to detect the virtual junction temperature $\left(T_{\mathrm{vj}}\right)$ that indicates the average temperature of the active semiconductor.

Prior to the high current tests, the TSEP is calibrated with a low current (i.e. $100 \mathrm{~mA}$ from the low current source). Tests are conducted in a thermal chamber with a controlled air flow and temperature. First, two healthy IGBTs and two healthy FWDs are tested from new at different junction temperatures. The recorded terminal voltages $\left(\mathrm{V}_{\mathrm{CE}}\left(T_{\mathrm{vj}}\right)\right.$ and $\left.\mathrm{V}_{\mathrm{F}}\left(T_{\mathrm{vj}}\right)\right)$ present a linear relationship with the juncture temperature, as shown in Fig. 6. Next, one bond wire is cut off and tests are repeated, followed by tests with two and three broken wires. Clearly, test results reveal that the terminal voltages are a function of junction temperature, in spite of broken wire faults. Similarly, a FWD is first tested from new, and then with 1, 2, and 3 broken wire faults successively. Its terminal voltage also shows a linear tendency with its junction temperature, regardless the broken wire faults. This is because the parasitic effect due to the device stray resistance is negligible and contributes little to the overall terminal voltage. Overall, the tests demonstrate the effectiveness of the TSEP method in predicting the junction temperature.

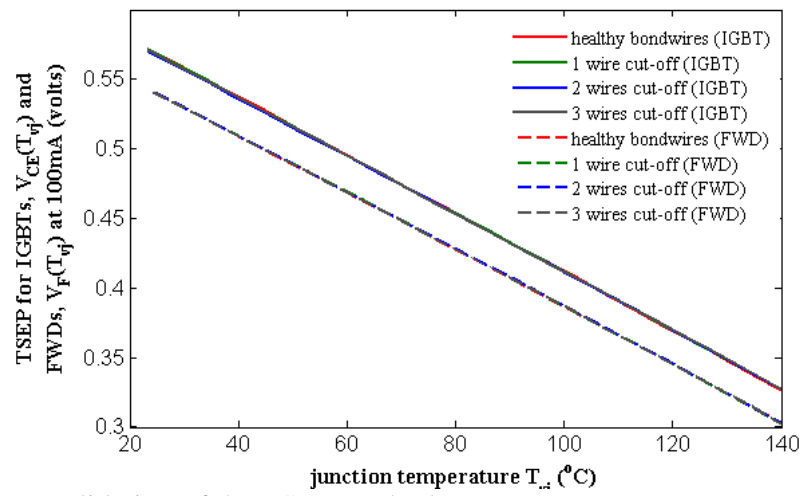

Fig. 6 Validation of the TSEP method. 
In theory, the on-state voltage drop is given by,

$$
V_{C E}\left(T_{j}, I_{C E}\right)=\left[V_{0}-a\left(T_{j}-T_{j 0}\right)\right]+\left[R_{0}+b\left(T_{j}-T_{j 0}\right)\right] \times I_{C E}
$$

where $V_{\mathrm{CE}}, T_{\mathrm{j}}, I_{\mathrm{CE}}$ are the on-state voltage drop, junction temperature, and load current, respectively. $V_{0}$ and $R_{0}$ represent the on-state voltage drop and metal-oxide-semiconductor (MOS) resistance at the reference junction temperature $T_{\mathrm{j} 0} ; a$ and $b$ are the temperature coefficients for $V$ and $R$, respectively.

When the juncture temperature increases at a low current $I_{\mathrm{CE}}$ (far below nominal), the second term in Eq (2) is negligible so that $V_{\mathrm{CE}}$ shows a reduction. This negative correlation is confirmed in Fig. 6 for both IGBTs and FWDs. Yet, when the juncture temperature increases at a high current $I_{\mathrm{CE}}$ (near nominal rating), the on-state voltage $V_{\mathrm{CE}}$ is dictated by the second term in Eq (2), giving a positive correlation. Thereby, these TSEP results can serve as a reliable calibration curve for each IGBT or FWD device and can be used later to estimate the device's junction temperature by measuring its terminal voltage at low currents.

\section{B. Sequence of TSEP and CM tests}

The proposed bond wire health monitoring method requires information of both the junction temperature (measured at low currents) and the voltage drop during forward conduction (measured at high load currents). This is achieved by generating current pulse trains for condition monitoring of bond wires. Initially a constant low DC current $\left(I_{l}\right)$ is injected into the DUT for TSEP measurements and then trains of designated high current pulses are injected and superimposed on the DC current for bond wire condition monitoring tests. These are demonstrated in Fig. 7.

During bond wire condition monitoring tests, the terminal voltage is directly measured at the end of the high current pulse. Three measurements are taken successively and averaged. The TSEPs are measured after the current is switched from high to low. The average value is then converted into the temperature $T_{\mathrm{vj}}$ using the predetermined TSEP calibration curves. Because some disturbances may present at the switching transients, an initial delay time is inserted to attain valid temperature information. As a consequence, there is a need to trace back to zero time. In this work, an extrapolation method is used on the basis of the device's cooling response curve.

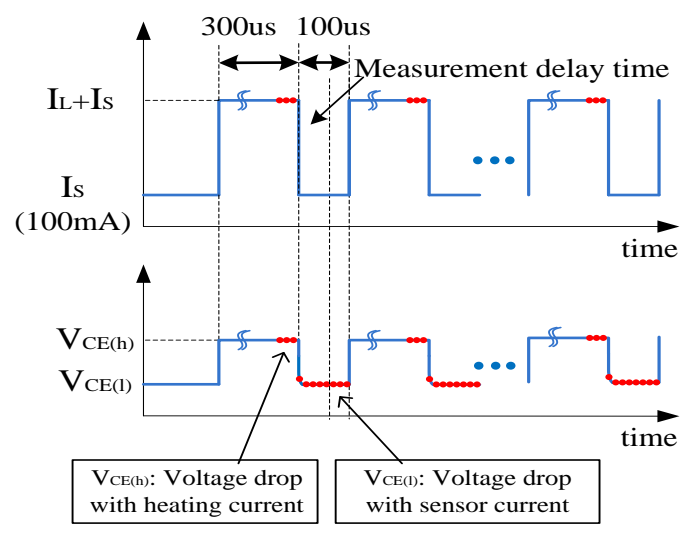

Fig. 7 Current pulse trains for bond wire health monitoring.

\section{Output voltage drifts}

The GDU is an integrated circuit that generates the voltage and current required for the switching of IGBT modules. Its output voltage $\left(V_{\mathrm{GE}}\right)$ can influence the IGBT device's output characteristics. The GDU consists of diodes, transistors, comparators and DC-DC converters, all of which could introduce temperature drift errors. In order to obtain meaningful precursor measurements, it is preferred to have a constant $V_{\mathrm{GE}}$ output but this is very challenging in practice. As presented in Table I, the ambient temperature for automotive applications changes over a large range in operation. The GDU output voltage is a function of the ambient temperature whilst its temperature coefficient can vary with device manufacturers.

Four GDUs (labeled A, B, C, D) are tested in this experiment to check the output voltage drift, with A and B from Concept Technology and C, D made in house. Fig. 8(a) shows the measured $V_{\mathrm{GE}}$ as a function of the ambient temperature. Positive temperature coefficients of $4.5 \mathrm{mV} /{ }^{\circ} \mathrm{C}$ (for $\mathrm{A}$ and $\mathrm{B}$ ) and $5.1 \mathrm{mV} /{ }^{\circ} \mathrm{C}$ (for $\mathrm{C}$ and $\mathrm{D}$ ) were obtained. It can be seen that the temperature coefficient is similar between the two GDUs from the same maker.

Fig. 8(b) presents $V_{\mathrm{GE}}$ variations with the ambient temperature at two different current levels. In this figure, the drift in $\mathrm{V}_{\mathrm{CE}(\mathrm{on})}$ can be as much as $15 \mathrm{mV}$ when the ambient temperature varies from $-20^{\circ} \mathrm{C}$ to $80^{\circ} \mathrm{C}$ with high currents. With low currents, this drift can still cause a junction temperature error of $2^{\circ} \mathrm{C}$ when $\mathrm{V}_{\mathrm{CE}}\left(T_{\mathrm{vj}}\right)$ is used for temperature estimation. Therefore, test results are temperature-compensated to cancel out the slope drift.

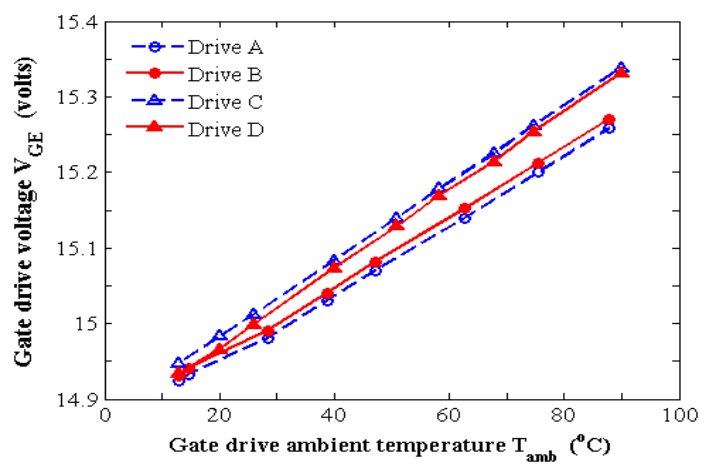

(a) Gate drive voltage as a function of ambient temperature

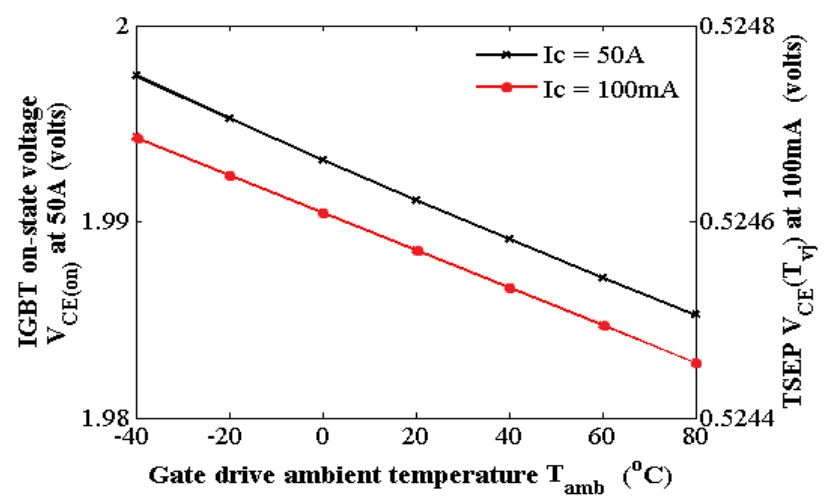

(b) On-state voltage as a function of ambient temperature Fig. 8 Output voltage drift.

\section{Health condition management}

As described previously, healthy baselines for IGBTs and diodes can be established from brand new. The forward voltage drop of the IGBTs and diodes is measured under different load currents and junction temperatures while the gate-emitter voltage is fixed (for the IGBTs). As shown in Fig. 9, the test results confirm that a liner approximation for the IGBTs and a cubic polynomial for the diodes are valid. 


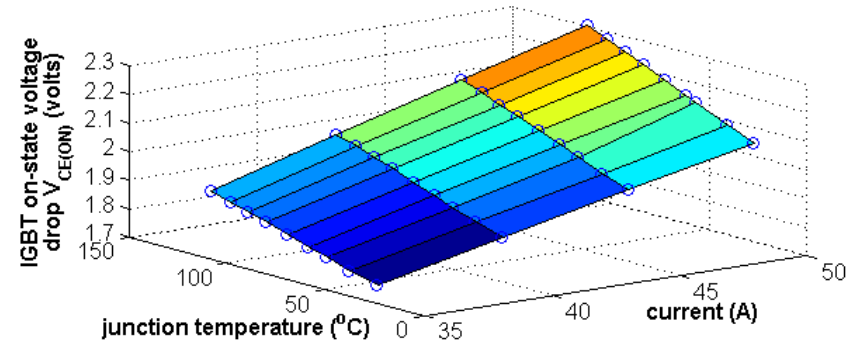

(a) IGBTs

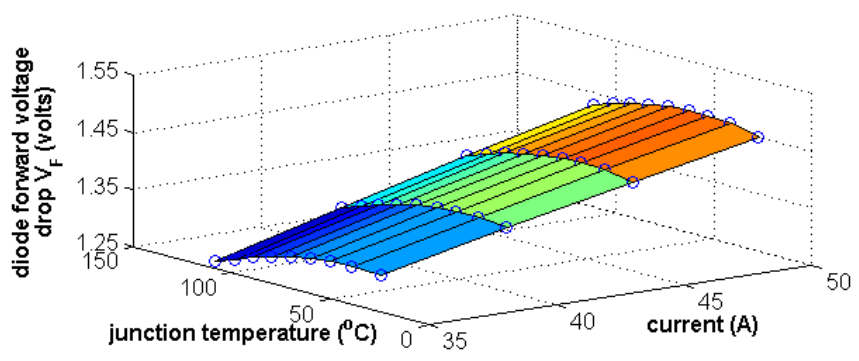

(b) Diodes

Fig. 9 Healthy device forward voltage surfaces as the baseline.

Mathematically, the voltage drop can be expressed by,

$$
V(I)=K_{0}(I)+K_{1}(I) \cdot T_{j}+K_{2}(I) \cdot T_{j}^{2}+\cdots+K_{n}(I) \cdot T_{j}^{n}
$$

where $V, T_{\mathrm{j}}$, and $I$ are the device forward voltage, junction temperature, and forward current, respectively. The coefficients $K_{0}(I), K_{1}(I), \cdots, K_{\mathrm{n}}(I)$ are determined by the curve fitting extrapolation method from experimental data. Importantly, $K_{0}(I)$ indicates an offset related to the bond wire resistance. Experimental results confirm the effectiveness of a liner approximation for the IGBTs and a cubic polynomial for the diodes.

Therefore, the device forward voltage for IGBTs at a given current can be simplified as,

$$
V(I)=V_{T 1}(I)-\left[V_{T 1}(I)-V_{T 2}(I)\right] \times \frac{T_{1}-T_{j}}{T_{1}-T_{2}}
$$

where $V, T_{\mathrm{j}}$, and $I$ are the device forward voltage, junction temperature, and load current, respectively. $V_{\mathrm{T} 1}$ and $V_{\mathrm{T} 2}$ indicate the reference voltage at junction temperature of $T_{1}$ and $T_{2}$, respectively.

Afterwards, three brand new IGBTs are tested in the thermal chamber at load current of $50 \mathrm{~A}$, gate voltages of $15 \mathrm{~V}$ and junction temperature of $40^{\circ} \mathrm{C}$ and $60^{\circ} \mathrm{C}$, respectively. A second set of tests are then performed for the three IGBTs with one broken bond wire. The test results are presented in Fig. 10(a). Their relative errors are calculated and shown in Fig. 10(b). The variations at both healthy and wear-out conditions are approximately $0.1 \%$, well below the commonly used failure criterion of $5 \%$.

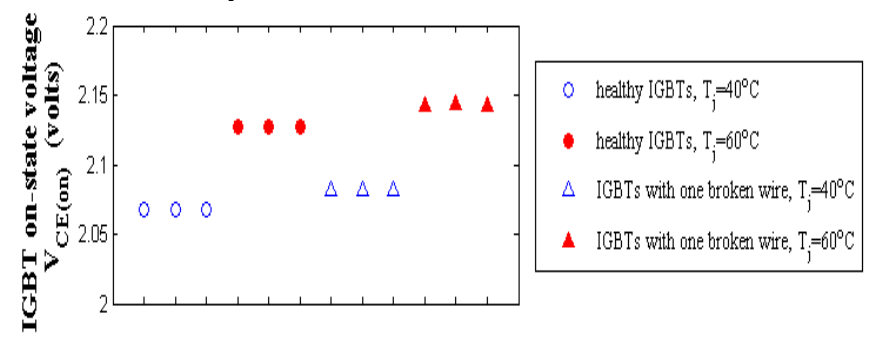

(a) IGBTs

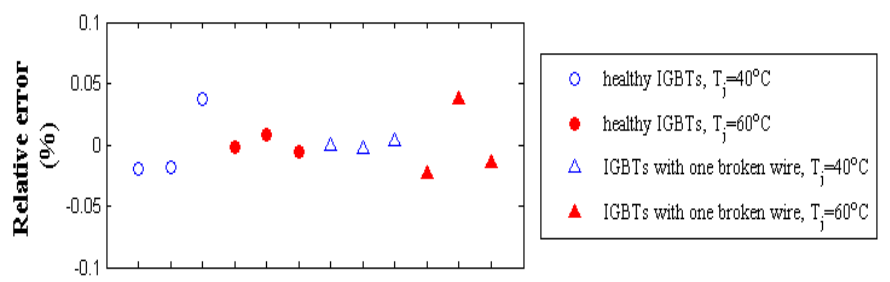

(b) Relative errors

Fig. 10 Measurement results for three IGBTs at junction temperatures of $40^{\circ} \mathrm{C}$ and $60^{\circ} \mathrm{C}$.

These test results clearly show that the developed method yields a high measurement accuracy. The measurements have very good agreement for the same batch of devices. Therefore, healthy baselines can be established by measuring one device out of a batch. A 3D look-up table can be generated from historical measurement data for health management purposes, taking account of the devices' initial condition, bond wire and operational conditions. For those IGBT modules without pre-determined look-up tables, a semi-supervised machine learning approach can be implemented as a compromise. In this situation, a quasi-healthy baseline is built in real time and a faulty condition is estimated empirically. The validity of this method is dependent on the accuracy of the training data. That is, any uncertainty in the training data may cause a false alarm or a measurement failure.

The prognostic and diagnostic parameters are plotted against the number of bond wire lift-offs in Fig. 11. It can be seen that the measured $V_{\mathrm{CE}(\mathrm{on})}$ increases by approximately $1 \%$ upon one broken wire; $2.5 \%$ for double broken wires; and $7 \%$ for triple broken wires. For the diode, the corresponding figures are $0.5 \%, 1.5 \%$ and $3 \%$, respectively, well above the measurement noise of approximately $1.2 \mathrm{mV}$ in the measurements. The operation of the IGBT under healthy and faulty conditions is demonstrated by the thermal images shown in Fig. 12.

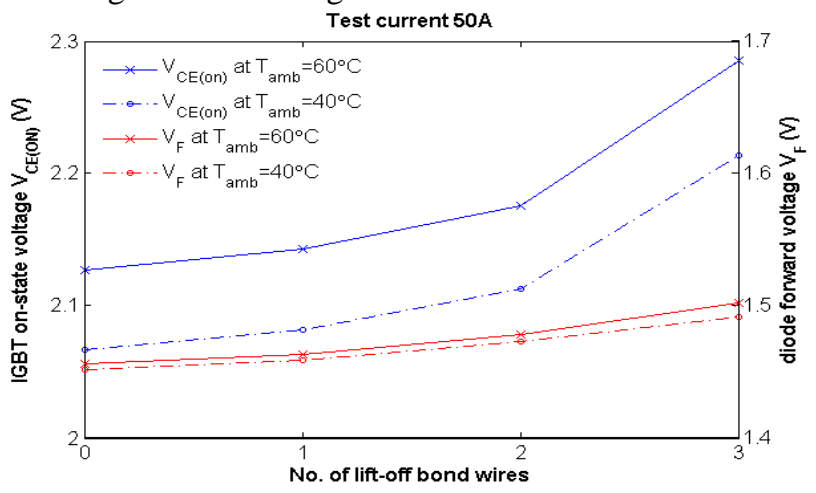

Fig. 11 Test results for bond wire lift-offs.

It can be also observed from Fig. 12 that as the number of broken wires increases, so is the remaining wires' temperature. Initially, the wires' temperature is lower than the chip's, as in Fig. 12(a) and (b). As the current density in the wire continues to rise, the wire gets hotter than the chip due to self-heating, as in Fig. 12(c) and (d). In addition, a non-uniform current distribution between the remaining wires is observed. Notably, if the $4^{\text {th }}$ wire (out of 6 wires) is lost to a fault, the remaining two will melt (Fig. 12(e)), resulting in an immediate open circuit fault and a complete 
device failure. As a consequence, an early warning signal is needed prior to this occurrence. That is, the time to flag up is when one half of the bond wires are broken, which corresponds to a 7\% increase in the on-state voltage from this study.

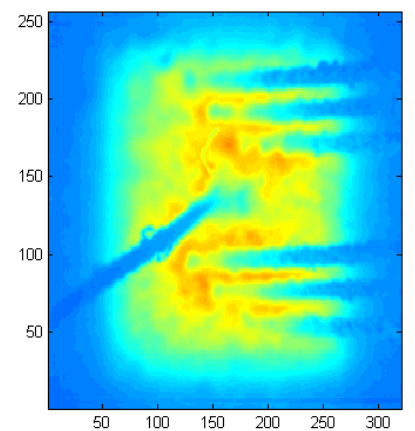

(a) Six healthy wires

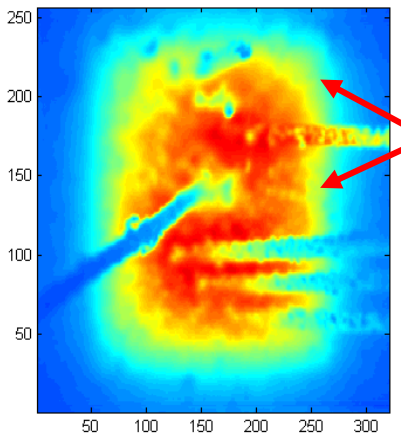

(c) Two broken wires

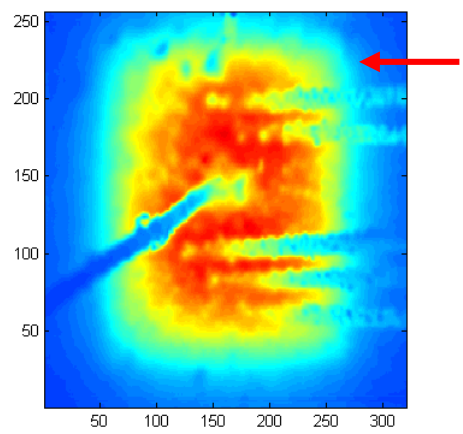

(b) One broken wire

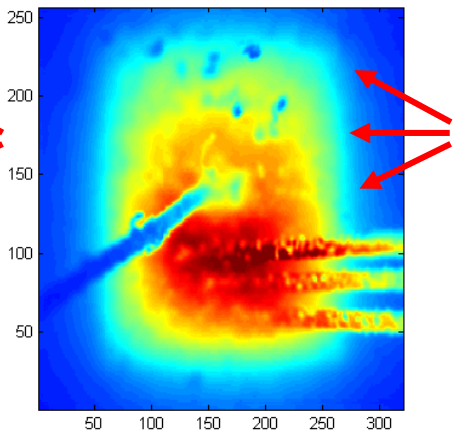

(d) Three broken wires

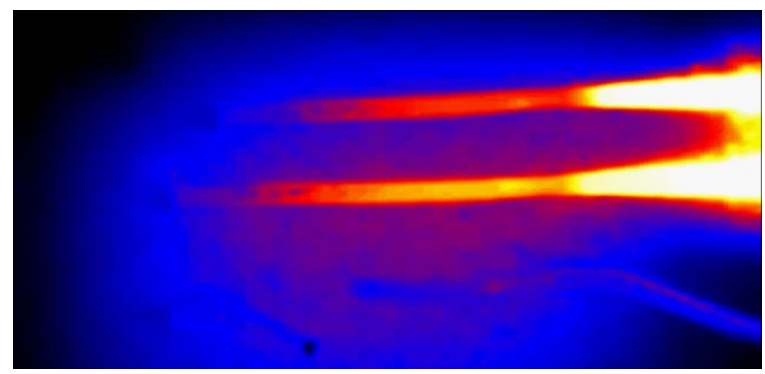

(e) Snapshot from a video clip for four broken wires

Fig. 12 Thermal images of an IGBT device with healthy and faulty bond wires.

Fig. 13 summaries the $\mathrm{CM}$ calculation procedure for bond wire faults in the form of a flow chart.

\section{CONCLUSIONS}

This paper has described an in-situ diagnostic and prognostic health monitoring method for IGBT power modules with a focus on the wire bonding faults and their failure mechanisms. Based on established analytical and empirical models of IGBTs, the proposed method has improved existing diagnostic and prognostic methods by providing in-service on-board prognostic solutions with a better measurement accuracy. The measuring circuits are capable of generating and injecting external DC currents into the power unit during the idle time, with low currents for TSEP measurements and high currents for $\mathrm{CM}$ tests. The total measurement duration is approximately 0.2 seconds so that the $\mathrm{CM}$ can be realistically carried out when the electric vehicle stops in red traffic conditions or routine servicing.

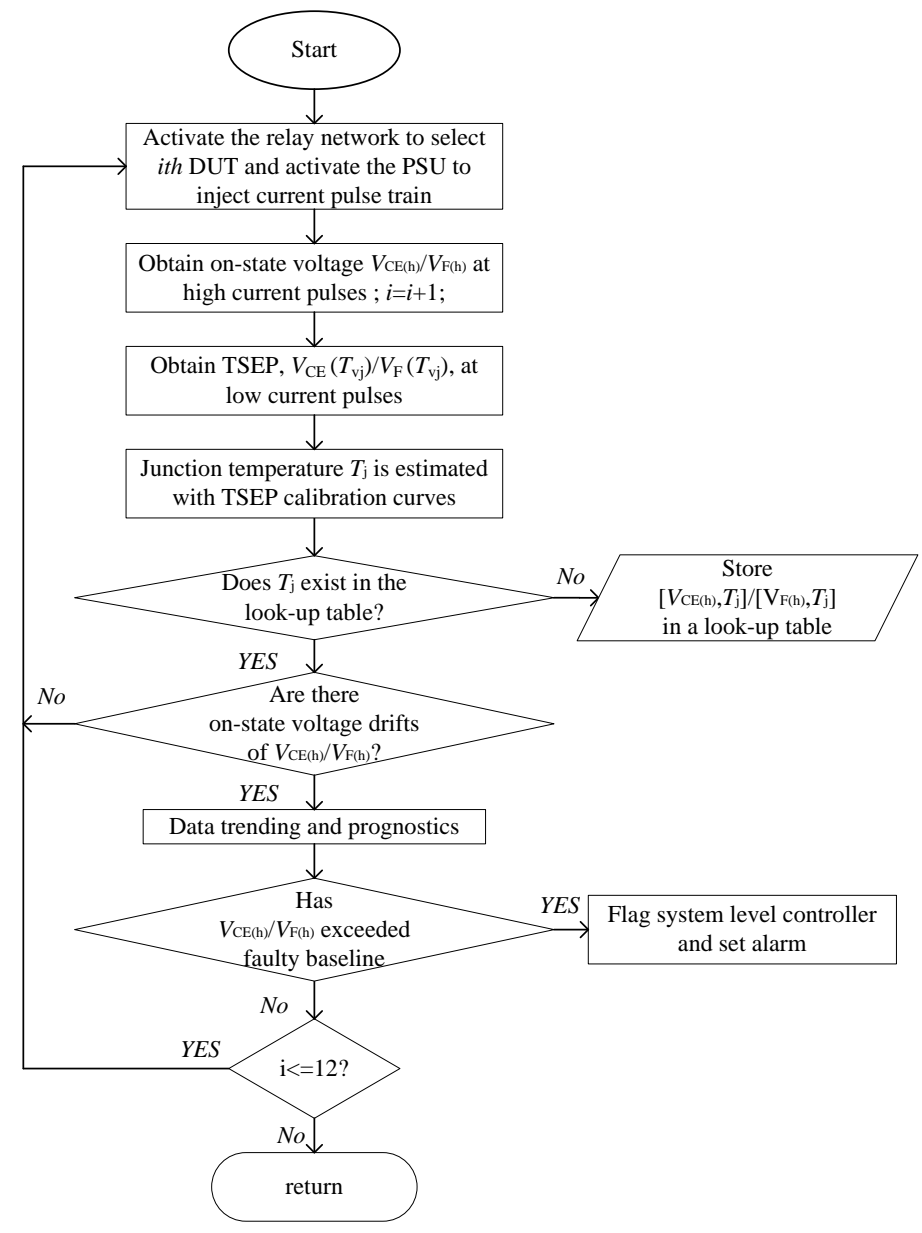

Fig. 13 Flow chart of the bond wire condition monitoring algorithm.

In the tests, the on-state voltage of the IGBTs and forward voltage drop of the FWDs are used as prognostic precursors to indicate the health condition of their bond wire connections. The bond wire faults are created by cutting off the wires without affecting the power device's healthy condition. Measured data are compared to predetermined healthy baselines to estimate the deterioration level of the devices. The test results suggest that the IGBT device may be able to operate with a loss of half the bond wires, corresponding to a $7 \%$ increase in the measured on-state voltage. This is the time to trigger a warning signal to the EV driver. If a further wire is broken, an irreversible failure will take place.

However, this study is limited to the wire bonding faults in the IGBT. In practice, the device itself may deteriorate with the wirebonds, giving rise to its resistance and the on state voltage observed from the measurement terminals. The experiential method developed from this work is still valid but the device's failure mechanisms and the fault-precursor correlation are required to establish fully.

\section{REFERENCES}

[1] N. H. Kutkut, D. M. Divan, D. W. Novotny, "Design considerations and topology selection for a 120-kW IGBT converter for EV fast charging," IEEE Trans. Power Electronics, vol. 13, issue 1, pp. 169-178, 1998.

[2] L. Solero, O. Honorati, F. Caricchi, F. Crescimbini, "Nonconventional three-wheel electric vehicle for urban mobility," IEEE Trans. Vehicular Technology, vol. 50, issue 4, pp. 1085-1091, 2001. 
[3] I. Aharon, A. Kuperman, "Topological overview of powertrains for battery-powered vehicles with range extenders," IEEE Trans. Power Electronics, vol.26, no.3, pp. 868-876, March 2011.

[4] J. Cao,Emadi, A, "A new battery/ultracapacitor hybrid energy storage system for electric, hybrid, and plug-in hybrid electric vehicles," IEEE Trans. Power Electronics, vol.27, no.1, pp. 122-132, Jan. 2012.

[5] L. Wang, Z. Wang, H. Li, "Asymmetrical duty cycle control and decoupled power flow design of a three-port bidirectional DC-DC converter for fuel cell vehicle application," IEEE Trans. Power Electronics, vol.27, no.2, pp. 891-904, Feb. 2012.

[6] L. Ni, D.J. Patterson, J.L. Hudgins, "High power current sensorless bidirectional 16-phase interleaved DC-DC converter for hybrid vehicle application," IEEE Trans. Power Electronics, vol.27, no.3, pp. 1141-1151, March 2012

[7] W. Qian, H. Cha, Z. Fang, L.M. Tolbert, "55-kW variable 3X DC-DC converter for plug-in hybrid electric vehicles," IEEE Trans. Power Electronics, vol.27, no.4, pp. 1668-1678, April 2012.

[8] Q. Hegazy, J. Van Mierlo, P. Lataire, "Analysis, modeling, and implementation of a multi-device interleaved DC/DC converter for fuel cell hybrid electric vehicles," IEEE Trans. Power Electronics, vol.27, no.11, pp. 4445-4458, Nov. 2012.

[9] B. Gu, J. Lai, N. Kees, C. Zheng; , "Hybrid-switching full-bridge DC-DC converter with minimal voltage stress of bridge rectifier, reduced circulating losses, and filter requirement for electric vehicle battery chargers," IEEE Trans. Power Electronics, vol.28, no.3, pp.1132-1144, March 2013.

[10] S. Bernet, "Recent developments of high power converters for industry and traction applications," IEEE Trans. Power Electronics, vol. 15, issue 6, pp. $1102-1117,2000$.

[11] Z. J. Shen, I. Omura, "Power semiconductor devices for hybrid, electric, and fuel cell vehicles," Proceedings of the IEEE, vol.95, no.4, pp.778-789, April 2007

[12] C. Mauro, "Selected failure mechanisms of modern power modules," Microelectronics Reliability, Vol. 42, issues 4-5, pp. 653-667, April-May 2002.

[13] U. Scheuermann, "Reliability challenges of automotive power electronics," Microelectronics Reliability, Vol. 49, Issues 9-11, pp. 1319-1325, Sept-Nov. 2009.

[14] B. Lu, S. K. Sharma, "A literature review of IGBT fault diagnostic and protection methods for power inverters," IEEE Trans. Industry Applications, vol. 45, issue 5, pp. 1770-1777, 2009.

[15] S.B. Lee, J. Yang, J. Hong, J.H. Yoo, B. Kim, K. Lee, J. Yun, M. Kim, K.W. Lee, E.J. Wiedenbrug, S. Nandi, "A new strategy for condition monitoring of adjustable speed induction machine drive systems," IEEE Trans. Power Electronics, vol.26, no.2, pp. 389-398, Feb. 2011.

[16] J.O. Estima, A.J. Marques Cardoso, "A new approach for real-time multiple open-circuit fault diagnosis in voltage-source inverters," IEEE Trans. Industry Applications, vol.47, no.6, pp. 2487-2494, Nov.-Dec. 2011.

[17] D. Xiang, L. Ran, P. Tavner, S. Yang, A. Bryant, P. Mawby, "Condition monitoring power module solder fatigue using inverter harmonic identification," IEEE Trans. Power Electronics, vol. 27, no. 1, pp.235-247, Jan. 2012.

[18] D. W. Brown, M. Abbas, A. Ginart, I. N. Ali, P. W. Kalgren, G. J. Vachtsevanos, "Turn-off time as an early indicator of insulated gate bipolar transistor latch-up," IEEE Trans. Power Electronics, vol. 27, no. 2, pp.479-489, Feb. 2012.

[19] S. Zhou, L. Zhou, P. Sun, "Monitoring potential defects in an IGBT module based on dynamic changes of the gate current," IEEE Trans. Power Electronics, vol. 28, no.3, pp.1479-1487, March 2013.

[20] Z. Zhou, M. S. Kanniche, S. G. Butcup, P. Igic, "High-speed electro-thermal simulation model of inverter power modules for hybrid vehicles," IET Electric Power Applications, vol. 5, no.8, pp. 636-643, September 2011.

[21] M. Trivedi and K. Shenai, "Failure mechanisms of IGBT's under short-circuit and clamped inductive switching stress," IEEE Trans. Power Electronics, vol. 14, pp. 108-116, 1999.

[22] D. C. Katsis, J. D. van Wyk, "Void-induced thermal impedance in power semiconductor modules: some transient temperature effects," IEEE Trans. Industry Applications, vol. 39, pp. 1239-1246, 2003.

[23] A. Lindemann, G. Strauch, "Properties of direct aluminum bonded substrates for power semiconductor components," IEEE Trans. Power Electronics, vol. 22, no. 2, pp. 384-391, March 2007

[24] S. Yang, D. Xiang, A. Bryant, P. Mawby, L. Ran, and P. Tavner, "Condition monitoring for device reliability in power electronic converters: a review," IEEE Trans. Power Electronics, vol. 25, pp. 2734-2752, 2010.
[25] M. Musallam, C. M. Johnson, "Real-time compact thermal models for health management of power electronics," IEEE Trans. Power Electronics, vol. 25, pp. 1416-1425, 2010.

[26] A. Morozumi, K. Yamada, T. Miyasaka, S. Sumi, Y. Seki, "Reliability of power cycling for IGBT power semiconductor modules," IEEE Trans. Industry Applications, vol. 39, pp. 665-671, 2003.

[27] Y. Yamada, Y. Takaku, Y. Yagi, I. Nakagawa, T. Atsumi, M. Shirai, I. Ohnuma, K. Ishida, "Reliability of wire-bonding and solder joint for high temperature operation of power semiconductor device," Microelectronics Reliability, vol. 47, pp. 2147-2151, 2007.

[28] N. Patil, J. Celaya, D. Das, K. Goebel, M. Pecht, "Precursor parameter identification for insulated gate bipolar transistor (IGBT) prognostics," IEEE Trans. Reliability, vol. 58, no. 2, pp.271-276, June 2009.

[29] D. Bin, J. L. Hudgins, E. Santi, A. T. Bryant, P. R. Palmer, H. A. Mantooth, "Transient electrothermal simulation of power semiconductor devices," IEEE Trans. Power Electronics, Vol. 25, Issue 1, pp. 237 - 248, 2010.

[30] V. Smet, F. Forest, J. J. Huselstein, F. Richardeau, Z. Khatir, S. Lefebvre, M. Berkani, "Ageing and failure modes of IGBT modules in high-temperature power cycling," IEEE Trans. Ind Electron, vol. 58, pp. 4931-4941, 2011.

[31] G. Chen, D. Han, Y. Mei, X. Cao, T. Wang, X. Chen, G, Lu, "Transient thermal performance of IGBT power modules attached by low-temperature sintered nanosilver," IEEE Trans. Device and Materials Reliability, vol.12, no.1, pp. 124-132, March 2012.

[32] X. Cao, G. Lu; K.D.T. Ngo, "Planar power module with low thermal impedance and low thermomechanical stress," IEEE Trans. Components, Packaging and Manufacturing Technology, vol.2, no.8, pp. 1247-1259, Aug. 2012.

[33] F. Vacher, B. Calvet, F. Mialhe, "Power cycling fatigue and lifetime prediction of power electronic devices in space applications," Microelectronics Reliability, Vol. 51, Issues 9-11, pp. 1985-1989, Sept-Nov. 2011.

[34] C. Carastro, C. Castellazzi, C. Clare, W. Wheeler, "High-efficiency high-reliability pulsed power converters for industrial processes," IEEE Trans. Power Electronics, vol.27, no.1, pp. 37-45, Jan. 2012.

[35] O. Schilling, M. Schafer, K. Mainka, M. Thoben, F. Sauerland, "Power cycling testing and FE modelling focused on $\mathrm{Al}$ wire bond fatigue in high power IGBT modules," Microelectronics Reliability, Vol. 52, Issues 9-10, pp. 2347-2352, Sept-Oct. 2012.

[36] R. Schmidt, C. König, P. Prenosil, "Novel wire bond material for advanced power module packages," Microelectronics Reliability, Vol. 52, Issues 9-10, pp. 2283-2288, Sept-Oct. 2012.

[37] S. Karimi, A. Gaillard, P. Poure, and S. Saadate, "FPGA-based real-time power converter failure diagnosis for wind energy conversion systems," IEEE Trans. Industrial Electronics, vol. 55, pp. 4299-4308, 2008.

[38] M. A. Rodríguez-Blanco, A. Claudio-Sánchez, D. Theilliol, L. G. Vela-Valdés, P. Sibaja-Terán, L. Hernández-González, J. Aguayo-Alquicira, "A failure-detection strategy for IGBT based on gate-voltage behavior applied to a motor drive system," IEEE Trans. Industrial Electronics, vol. 58, no. 5, pp.1625-1633, May 2011.

[39] A. Bryant, S. Yang, P. Mawby, D. Xiang, L. Ran, P. Tavner, P. Palmer, "Investigation into IGBT $\mathrm{dV} / \mathrm{dt}$ during turn-off and its temperature dependence," IEEE Trans. Power Electronics, vol.26, no.10, pp. 3019-3031, Oct. 2011.

[40] I. Baraia, J. Barrena, G. Abad, J.M. Canales Segade, U. Iraola, "An experimentally verified active gate control method for the series connection of IGBT/diodes," IEEE Trans. Power Electronics, vol.27, no.2, pp. 1025-1038, Feb. 2012.

[41] N. M. Vichare and M. G. Pecht, "Prognostics and health management of electronics," IEEE Trans. Components and Packaging Technologies, vol. 29, pp. 222-229, 2006.

[42] D. Goodman, B. Vermeire, J. Ralston-Good, and R. Graves, "A board-level prognostic monitor for MOSFET TDDB," the 2006 IEEE Aerospace Conference, pp. 1-6, March 2006.

[43] V. A. Sankaran, C. Chen, C. S. Avant, and X. Xu, "Power cycling reliability of IGBT power modules," the Thirty-Second IEEE Industry Applications IAS Annual Meeting, vol.2, pp. 1222-1227, 1997.

[44] M. Held, P. Jacob, G. Nicoletti, P. Scacco, and M. H. Poech, "Fast power cycling test for insulated gate bipolar transistor modules in traction application," International Journal of Electronics, vol. 86, pp. 1193-1204, 1999.

[45] O. Salmela, "Acceleration factors for lead-free solder materials," IEEE Trans. Components and Packaging Technologies, vol. 30, pp. 700-707, 2007. 
[46] L. Yang, J. B. Bernstein, and T. Koschmieder, "Assessment of acceleration models used for BGA solder joint reliability studies," Microelectronics Reliability, vol. 49, pp. 1546-1554, 2009.

[47] R. Bayerer, T. Herrmann, T. Licht, J. Lutz, and M. Feller, "Model for power cycling lifetime of IGBT modules - various factors influencing lifetime," the 5th International Conference on Integrated Power Systems (CIPS), pp. $1-6,2008$.

[48] M. Ciappa, F. Carbognani, W. Fichtner, "Lifetime prediction and design of reliability tests for high-power devices in automotive applications," IEEE Trans. Device and Materials Reliability, vol.3, no.4, pp. 191- 196, Dec. 2003.

[49] A. T. Bryant, P. A. Mawby, P. R. Palmer, E. Santi, and J. L. Hudgins, "Exploration of power device reliability using compact device models and fast electro-thermal simulation," the Forty-First IEEE Industry Applications Conference (IAS) Annual Meeting, October 8-12, Tampa, FL, United States, pp. 1465-1472, 2006.

[50] R. C. Blish Ii, "Temperature cycling and thermal shock failure rate modeling," the 35th Annual IEEE International Reliability Physics Symposium, April 8-10, Denver, CO, USA, pp. 110-117. 1997.

[51] Q. Jin and J. B. Bernstein, "Non-arrhenius temperature acceleration and stress-dependent voltage acceleration for semiconductor device involving multiple failure mechanisms," the IEEE International Integrated Reliability Workshop (IIRW), Final Report, October 16-19, South Lake Tahoe, CA, US, pp. 93-97, 2006.

[52] P. M. Fabis, D. Shun, and H. Windischmann, "Thermal modelling of diamond-based power electronics package," the 15th Annu. IEEE Semicond. Therm. Meas. Manage. Symp., pp. 98-104, 1999.

[53] J. Onuki, M. Koizumi, and M. Suwa, "Reliability of thick Al wire bonds in IGBT modules for traction motor drives," IEEE Trans. Advanced Packaging, vol. 23, pp. 108-112, 2000.

[54] Y. Xiong, X. Cheng, Z. J. Shen, C. Mi, H. Wu, and V. K. Garg, "Prognostic and warning system for power-electronic modules in electric, hybrid electric, and fuel-cell vehicles," IEEE Trans. Industrial Electronics, vol. 55, pp. 2268-2276, 2008.

[55] H. Lu, C. Bailey, and C. Yin, "Design for reliability of power electronics modules," Microelectronics Reliability, vol. 49, pp. 1250-1255, 2009.

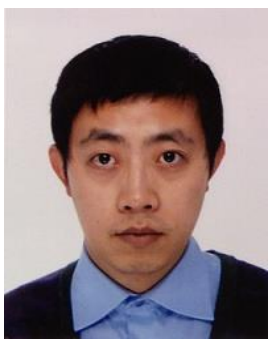

Bing Ji (M'13) received the M.Sc. and Ph.D. degrees in electrical and electronic engineering from Newcastle University, England, in 2007 and 2012, respectively. He was a power electronics engineer with a UK low-emission vehicle company from 2012, where he worked on powertrain development for hybrid electric vehicles and battery management systems. Since Jan. 2013, he is an EPSRC Postdoctoral Researcher at Newcastle University, where he is involved with design of the calorimetric measurement system for high efficiency power converters and electric machines. His research interests are reliability and diagnosis of power semiconductor devices, batteries and power converter systems, electro-thermal modeling, high-density converter integration and thermal management for vehicle applications. He is also a member of the IET.

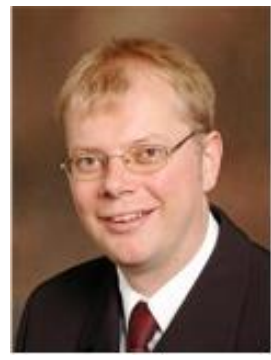

Volker Pickert (M'04) received the Dipl.-Ing. degree in electrical and electronic engineering from the Rheinisch-Westfaelische Technische Hochschule, Aachen, Germany in 1994, and the Ph.D. degree from Newcastle University, Newcastle upon Tyne, UK in 1997. From 1998 to 1999 he was application engineer with Semikron International, Nuremberg, Germany; and from 1999 to 2003 he was group leader at Volkswagen, Wolfsburg, Germany, and responsible for the development of electric drives for electric vehicles. In 2003, he was appointed as Senior Lecturer within the Power Electronics, Drives and Machines Research Group at Newcastle University and in 2011 he became Professor of Power Electronics. Prof Pickert has published over 80 papers in the area of power electronics and he is the recipient of the IMarEst Denny Medal for the best paper in the Journal of Marine Engineering and Technology in 2011. He was chairman of the biannual international IET conference on Power Electronics, Machines and Drives in 2010. $\mathrm{He}$ is an executive steering member of the IET PGCU network and a member of the EPE. His current research includes power electronics for automotive applications, thermal management, fault tolerant converters and advanced nonlinear control.

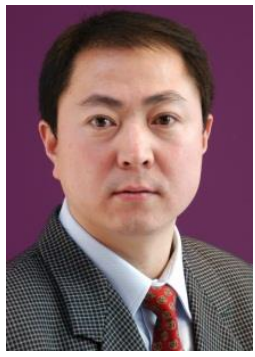

Wenping Cao (M'05-SM'11) (correspondence author) received the BEng in electrical engineering from Beijing Jiaotong University, Beijing, China, in 1991; and the $\mathrm{Ph} . \mathrm{D}$. degree in electrical machines and drives from the University of Nottingham, Nottingham, U.K., in 2004. $\mathrm{He}$ is currently a Lecturer with Newcastle University, Newcastle upon Tyne, U.K. His research interests are in thermal performance of electric machines, drives and power electronics.

Dr. Cao serves as an associate editor for IEEE Transactions on Industry Applications, IEEE Industry Applications Magazine as well as an editorial board for International Journal of Engineering and Technology (IJET), and the Journal of Electrical \& Electronics (JEE). He is also a member of the Institution of Engineering and Technology (IET) and a Fellow of Higher Education Academy (HEA).

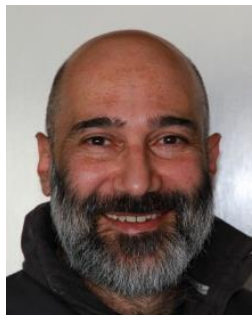

Bashar Zahawi (M'96-SM'04) received the BSc and $\mathrm{PhD}$ degrees in electrical and electronic engineering from Newcastle University, England, in 1983 and 1988, respectively. From 1988 to 1993 he was a design engineer with a UK manufacturer of large variable speed drives and other power conversion equipment. In 1994, he was appointed as a Lecturer in Electrical Engineering at the University of Manchester, and in 2003 he joined the School of Electrical and Electronic Engineering at Newcastle University, England, as a Senior Lecturer. His research interests include small scale generation, power conversion and the application of nonlinear dynamical methods to electrical circuits and systems. Dr Zahawi is a chartered electrical engineer and the recipient of the Crompton Premium awarded by the Institution of Electrical Engineers (IEE) and the Denny Medal awarded by the Institute of Marine Engineering, Science \& Technology (IMarEST). 